\title{
Multiscale effects caused by the fracturing and fragmentation of rock blocks in rock mass movement: Implications for rock avalanche propagation
}

\author{
Qiwen Lin ${ }^{1,2}$, Yufeng Wang ${ }^{1,2,3}$, Yu Xie ${ }^{1}$, Qiangong Cheng ${ }^{1,2,3}$, Kaifeng Deng ${ }^{1}$
}

$5{ }^{1}$ Department of Geological Engineering, Southwest Jiaotong University, Chengdu, Sichuan, 610031, China

${ }^{2}$ Key Laboratory of High-Speed Railway Engineering, Ministry of Education, Chengdu, Sichuan, 610031, China

${ }^{3}$ State-Province Joint Engineering Laboratory of Spatial Information Technology of High-Speed Rail Safety, Chengdu, Sichuan, 610031, China

Correspondence to: Yufeng Wang (wangyufeng@swjtu.edu.cn)

10 Abstract. Fracturing and fragmentation of rock blocks are important and universal phenomena during the propagation of rock avalanches. Here, the movement of a rectangular rock block characterized by different joint sets along an upper inclined and lower horizontal traveling path is simulated, aiming to quantify the fracturing and fragmentation effect of the block in propagation. The preset of the joint sets allows the block to break along the weak joint planes at the very beginning of fragmentation. With this design, the fracturing and fragmentation processes in the sliding rock block and their influences on

15 energy transformation in the system are investigated. The results show that fragmentation can alter the horizontal velocities and kinetic energies of fragments in the block system with the front subblocks being accelerated and the rear part being obviously decelerated. Such energy conversion and transfer between the front and rear subblocks is attributed to the elastic strain energy release and transformation caused by fragmentation. The energy transfer induced by fragmentation is more efficient than that induced by collision. A positive trend between the kinetic energy increase of the front subblocks induced

20 by fragmentation and the rock strength can be fitted well with a linear function. However, no good relationship is reached between the strain energy incremental ratio and travel distance, which implies that the fragmentation effects may be weakened with the increasing complexity of the fragmenting rock mass system. Three elastic strain wave release effects caused by rock fragmentation are further inferred and discussed based on simulation results.

\section{Introduction}

25 Rock avalanches are one of the most destructive geophysical flows and can effectively shape mountainous landscapes on Earth and other planetary surfaces (Lucas et al., 2014; Crosta et al., 2018). They have also caused numerous casualties and large economic losses in recent decades due to their extremely long travel distances (Evans et al., 2007; Fan et al., 2017). Hypermobility, i.e., exceptionally long runout distances of rock avalanches, is usually quantified by the apparent friction coefficient (H/L, where $\mathrm{H}$ and $\mathrm{L}$ represent the vertical and horizontal distances between the crest of the failure mass and the distal point of deposition, respectively) (Heim, 1932). When the volume of the failure mass $>10^{6} \mathrm{~m}^{3}, \mathrm{H} / \mathrm{L}$ shows a decrease 
with volume, leading to hypermobility in mega rock avalanches. The hypermobility of rock avalanches has drawn much scientific interest because it cannot be simply solved by a Coulomb frictional model of a sliding rock block (Legros, 2002).

To explain the hypermobility of rock avalanches, many dynamic mechanisms have been proposed. Some mechanisms involve fluid media, such as air (Kent, 1966), water (Wang et al., 2002; Hungr and Evans, 2004), a fluid-like fine grain matrix (Hsü, 1975), melted rock or vapor (Habib, 1975; Goguel, 1978; Hu et al., 2018), thermal pressurization and thermal moisture fluidization (Wang et al., 2017, 2018a). Others invoke the interactions of materials in avalanche systems, such as shearing and impacting between a sliding mass and undulate path-generated acoustic fluidization (Melosh, 1979; Collins and Melosh, 2003), shearing between a rock mass and the ground (Foda, 1994; Wang et al., 2015), shearing between particles in the basal layer (Preuth et al., 2010), momentum transfer caused by collisions of particles or different parts of the rock mass

40 (Heim, 1932; Van Gassen et al., 1989; Miao et al., 2001), and dispersive pressure caused by dynamic fragmentation (Davies et al., 1999; Davies and McSaveney, 2009). Nevertheless, a universal consensus is still far beyond reach (Weidinger et al., 2014). For a rigorous mechanism to explain hypermobility, geological evidence coming from the travel path and the deposition of the sliding mass must be considered. Many field observations suggest that the following phenomena commonly occur in large rock avalanches (Weidinger et al., 2014; Dufresne et al., 2016):

45 (1) "Volume effect", where the apparent friction coefficient $(\mathrm{H} / \mathrm{L})$ decreases as the volume of the rock mass increases (Scheidegger, 1973);

(2) Intense fragmentation in the deposit (Davies et al., 1999);

(3) Close packing of grains during movement (dense grain flows) (Pudasaini and Hutter, 2007);

(4) "Inverse grading" at depth in the deposit (Heim, 1932; Cruden and Hungr, 1986);

50 (5) Shear stress concentrated in basal facies (Dufresne et al., 2016);

(6) "Jigsaw puzzle" structures and local shear bands in the deposit (Shreve, 1968);

(7) Preservation of the host rock massif structure in the rock avalanche deposit (Heim, 1932; Strom, 2006).

Unfortunately, few mechanisms account for the hypermobility of rock avalanches and can explain the formation of these main features listed above. Some mechanisms even contradict geological evidence (McSaveney and Davies, 2006). Among these mechanisms, dynamic fragmentation, first proposed by Davies et al. (1999), has received sustained investigation and supplementation (McSaveney and Davies, 2006; Davies and McSaveney, 2009; Zhao et al., 2017). This runout-enhanced mechanism is based on solid geological evidence that intense fragmentation occurs universally in the deposits of rock avalanches; meanwhile, this mechanism does not conflict with the main structural features in the deposits of rock avalanches. Moreover, special deposit structures, including inverse grading, jigsaw structures and local shear bands, are closely related to

60 the fragmentation process of avalanches (McSavaney and Davies, 2006; Dufresne et al., 2016; Wang et al., 2018b).

Recently, fragmentation and related deposit characteristics and fragmentation effects of rock avalanches have been widely investigated via field events (Pollet and Schneider, 2004; Locat et al., 2006; Crosta et al., 2007; Perinotto et al., 2015; Wang et al., 2019, 2020), laboratory experiments (Imre et al., 2010; Bowman et al., 2012; Haug et al., 2016) and numerical simulations (Rait et al., 2012; De Blasio and Crosta, 2015; Langlois et al., 2015; Zhao et al., 2017, 2018). On the one hand, 
65 fracture and fragmentation are considered to consume part of the kinetic energy. The fragmentation process is estimated to dissipate 1-30\% of the total potential energy in a rock avalanche (Locat et al., 2006; Crosta et al., 2007; De Blasio et al., 2018), but these authors unrealistically truncate their rock avalanche particle-size distributions (as stated by Davies et al. (2019a)). When the existence of submicron particles is included in the estimate, the amount of energy supposedly dissipated by fragmentation rises to substantially exceed $100 \%$ of the initially available energy (Davies et al., 2019b). On the other hand, some studies have shown that fragmentation may enhance the travel distance of the distal part of the sliding mass (Bowman et al., 2012; De Blasio and Crosta, 2015; Haug et al., 2016). The flow structure of fine particle concentration caused by intense fragmentation will also facilitate the mobility of fragment flow (Langlois et al., 2015; Lai et al., 2018). For those who agree with the mobility-enhanced effects of dynamic fragmentation, elastic strain energy release caused by fragmentation is considered to be a key dynamic process accounting for hypermobility (Davies and McSavaney, 2009; De

75 Blasio and Crosta, 2015; Zhao et al., 2017). Based on the theory of rock dynamics and fracture mechanics, rock cracking occurs when the peak of the stress wave exceeds the strength of the rock itself, and then, part of the strain energy is consumed by cracking or so-called new surface generation, while the remaining elastic strain energy may release outward as elastic stress waves or transfer to the kinetic energy of the fragments (Grady and Kipp, 1987; Zhang et al., 2000; Ghaffari et al., 2019). McSaveney and Davies (2006) proposed that elastic energy release induced by dynamic fragmentation may

80 generate universe outward dispersed stress, which can offset part of the overburden pressure and result in lower shear resistance. Perinotto et al. (2015) examined the fractal dimension and circularity variation with the deposit distance of the La Reunion volcanic debris avalanche and then indicated that the exceptional mobility of the debris avalanche is caused by the comprehensive effect of dynamic disintegration-induced elastic energy release of larger clasts and frictional reduction due to the interactions between fragmentation-formed fine particles. Davies et al. (2019a) stated that the main fraction of the energy

85 acting on fragmented rock radiates to the surrounding material as elastic body waves when rock fragments, while only a small fraction of the energy is dissipated by newly created fragment surfaces. However, the experimental results from highspeed rotary shear tests conducted by Hu et al. (2020) indicate that the hypermobility of fragmenting granular flows is not directly induced by grain fragmentation but may be invoked by the "after-fragmentation" effects (e.g., a fractal grain-size distribution).

90 As mentioned above, many core issues of fragmentation dynamics and related fragmentation effects are still controversial and unsolved (Davies and McSaveney, 2009; Haug et al., 2016). For example, how does the elastic strain energy related to fragmentation transform during the propagation of rock mass, and what are the effects on surrounding rock mass? Do the runout-enhancing effects of elastic strain energy release via fragmentation offset and even surpass the runout-hindering effects of energy consumption caused by fragmentation? To further understand these questions, studies on the energy 95 conversion process of rock avalanches caused by rock fragmentation and its effects on the fragmenting block system are conducted here. In this study, we reproduce the fragmenting process of a sliding rock mass with different joint sets using a discrete element method (DEM) model, aiming to investigate the microscopic energy conversion process caused by dynamic fragmentation. After that, the dynamic fragmentation effects in real rock avalanches are discussed based on the numerical 
simulation results. Around these contents, section 2 provides details about the DEM setup. In section 3, the results derived from numerical simulations are presented. Section 4 is mainly focused on the discussion of the implications of the results for the fragmentation effects in natural rock avalanches.

\section{DEM model setup}

Previous studies have proven that DEM models can successfully simulate the dynamic behavior of dry granular flows (Silbert et al., 2001; Bi et al., 2005; Morgan and McGovern, 2005; Utili et al., 2015; Kermani et al., 2015; Lai et al., 2017), crack nucleation and propagation of rock blocks under different loading rates (Yoon 2007; Wang and Tonon, 2011; Shen et al., 2017; Ma et al., 2018) and the fragmentation process of rock avalanches (Thompson et al., 2010; Lo et al., 2011; Li et al., 2012; Deng et al., 2016; Zhao and Crosta, 2018). Therefore, the commercial DEM software particle flow code in two dimensions (PFC2D) is employed to run all of the simulations discussed here (Cundall, 1971; Cundall and Strack, 1979).

In PFC2D, the basic element is a disc, and granular material is simulated as an assembly of discs. The behavior of a granular flow is determined by the motion and interaction of disc aggregates. In general, rock blocks are modeled as cemented tightly packed discs via a linear parallel bond model (PBM), presenting brittle fracture characteristics as the bonds instantly break and disappear once the force acting on the bond reaches the failure criterion (Potyondy and Cundall, 2004). After the bond breaks, the interaction between dispersed particles is replaced by a linear model, in which the motions of particles and blocks are controlled by Newton's second law of motion. Therefore, dynamic fragmentation can be well simulated by this bondedparticle model (Zhao et al., 2017, 2018). Only the elastic strain energy carried by the bond vanishes after macrocracks develop during fragmentation in the rock mass; meanwhile, the remaining elastic strain energy stored in unbroken bonds and the overleap deformation of particles will still transform, accumulate and release. This process provides exceptional opportunities to observe and analyze the conversion of elastic strain energy during the fracture and fragmentation process in the transport of brittle materials during the movement of fragmentable blocks (Potyondy and Cundall, 2004; Timar et al., 2012; Shen et al., 2017).

A schematic view of the model configuration is shown in Fig. 1. As exhibited in Fig. 1, the traveling path of a rectangular rock block is mainly composed of an inclined slope and a horizontal plane. An arc connection path with a radius of $0.1 \mathrm{~m}$ is added between two planes. Joints with different strengths and numbers are predesigned in the rock blocks. Instead of trying to replicate the complicated fragmentation processes that occur in real rock avalanches, the aims of this simplified configuration are to provide an opportunity to investigate the detailed microprocesses of fragmentation and the effects of pre-existing joints on a sliding-fragmenting rock mass system. The inset table in Fig. 1 gives the forms and parameters of predesigned joints. With the design of pre-existing weak joints in the rock block, the rock block will break mainly along the weak joint planes at the initial stage of fragmentation during motion (we define the intact block as cut by joints into subblocks). The energy conversion of the block system and the variation in the motion of subblocks can be clearly recorded and analyzed. The blocks with joints of no tensile strength (T1, T4) aim to represent the separation process of blocks that 
have been fractured, while the blocks that have joints with tensile strength are intended to simulate the blocks that crack along joints and then separate. This point is very important for the following description of the DEM setup, the results and discussion. Note that the fracturing of a rock block along specific directions or weak planes does not change the nature of rock fragmentation.

135 Choosing the microparameters of the linear parallel bond model here is based on the numerical procedure applied in Potyondy and Cundall (2004), in which the macroproperties of Lac Du Bonnet granite (Martin, 1993) are used. Uniaxial compressive tests and uniaxial tensile tests are employed to calibrate the microparameters in the simulation. The input values of microscopic parameters in the DEM model are selected by trial and error to ensure that the mechanical characteristics of the granite block in the simulation match those of the real Lac Du Bonnet granite. Table 1 shows the input microparameter

140 values of the DEM model. The uniaxial compressive strength, Young's modulus, Poisson's ratio and tensile strength of the rock block in the simulation are 200.4 MPa, 67.6 GPa, 0.259 and 40.97 MPa, respectively. These microparameters in the DEM model match well with the mechanical properties of a natural granite block (Martin, 1993), which has a relatively high tensile strength. For 2D DEM simulations, which differ from the traditional plane strain or plane stress situation, there are no direct laboratory experimental results that can be used for the calibration of damping values. Based on our previous 3D DEM

145 simulation and other similar simulations (Giani et al. 2004; Lo et al., 2014; Murugaratnam et al. 2015; Lin et al., 2020a), the local, normal, and shear viscous damping terms are set to $0.06,0.36$, and 0.11 , respectively. Note that viscous damping affects only the efficiency of energy dissipation and the runout distance of sliding blocks (Johnson et al., 2016); the dynamics of the block system and the fragmentation mechanism of the rock block are not changed. Each simulation shows a typical rock fracture and deposition process, which validates the applicability of these microparameters for the DEM model.

150 For the traveling path, the inclined plane is a frictionless rigid wall with a slope angle of $30^{\circ}$, while the friction angle of the arc and horizontal planes is $30^{\circ}$ to dissipate kinetic energy. Similar to Zhao et al. (2017, 2018) and Bowman et al. (2012), the size of the rock block is $94 \mathrm{~mm} \times 45 \mathrm{~mm}$. The drop height $(H)$ is $0.12 \mathrm{~m}$. The gravitational acceleration $\left(g^{\prime}\right)$ is enhanced to $1962 \mathrm{~m} / \mathrm{s}^{2}(200 \mathrm{~g})$ to mimic the real stress field. For the predesigned joints shown in Fig. 1, T1, T2 and T3 represent a rock block with one joint, which varies in the tensile strength of the joint. T4, T5 and T6 represent a rock block with two joints

155 and vary in the tensile strength of the joints. These joints equally divide the entire block. The tensile strengths of the joints $(\sigma)$ are $0 \mathrm{MPa}$ (T1 and T4), 4.39 MPa (T2 and T5) and 8.61 MPa (T3 and T6). The joints with different tensile strengths are defined by reducing the bond cohesion within the joint plane, while the joint planes have a width of $1.5 \mathrm{~mm}$ ( 3 times the mean size of particles) and a length of $45 \mathrm{~mm}$ (the same as the block's height). The joints with no tensile strength are simply defined by debonding the particles within the joint plane. Meanwhile, the block strength is unchanged (200.4 MPa) for all simulation conditions. Table A.1 in the appendix shows the main variables used in this study. 


\section{Results}

\subsection{Fracture and fragmentation of rock block}

In this section, the processes of fractures along pre-existing joints and fragmentations of sliding masses are examined. Considering that all of the tests experience a similar process, only the evolutions of T1 and T3 are presented in Fig. 2 and

165 described in detail in this section. For the T1 sample, local fragmentation $\left(S_{1 \mathrm{~T} 1}\right)$ first occurred at the frontal bottom as it reached the arc segment of the travel path (Fig. 2a). After that, further local fragmentation occurs at the same part of the block due to impact. Soon, fracture along the pre-existing joint began to occur, which is called the separating stage $\left(\mathrm{S}_{2 \mathrm{~T} 1}\right)$. In this stage, the joint fractures from the bottom to the top surface of the block with time. As the joint was fractured completely, the front subblock was pushed forward by the rear subblock, and local fragmentation occurred at the middle top surface

$170\left(S_{3 T 1}\right)$. Finally, both of the subblocks moved and deposited along the horizontal plane with different degrees of further fragmentation. For T3 characterized by higher tensile strength, similar processes of fragmentation and separation were also observed (Fig. 2b). Similar to T1, T3 also showed local fragmentation at the frontal bottom of the block as it slid onto the arc path $\left(\mathrm{S}_{1 \mathrm{T3}}\right)$. Subsequently, more intensive local fragmentation occurred $\left(\mathrm{S}_{2 \mathrm{~T} 3}\right)$. After a while fracture along the pre-existing joint finally occurred, which is called the cracking stage $\left(\mathrm{S}_{3 T 3}\right)$.

$175 \mathrm{~S}_{2 \mathrm{~T} 1}$, the separating stage, represents two tightly packaged rock blocks disintegrating and separating along a specific orientation, which may be any type of discontinuity (rock blocks do not fragment but separate). $\mathrm{S}_{3 \mathrm{~T} 3}$, the cracking stage, represents the rock block experiencing dynamic cracking and "fragmentation" along a specific orientation (rock blocks fragment and separate). These two stages are directly compared to examine the dynamic fragmentation effect of rock blocks on the mesoscale and the rock fragment system dynamics in the following. Note that the travel distance of the center of mass for $\mathrm{T} 1$ is slightly shorter than that for $\mathrm{T} 3$.

To determine the exact times when these fragmentation processes occur, especially the times when the blocks separated along the joints, six monitoring particles near the joint were selected to record their velocity variations. The monitoring particles are symmetrically distributed along both sides of the joint and equally spaced in the vertical direction, as shown in the inset picture in Fig. 3a. The distance between the joint and monitoring particles is approximately twice the mean size of

185 the particles. Following Zhao et al. (2017), nondimensional parameters were employed. The sliding time $(t)$ is normalized by $\left(2 H / g^{\prime}\right)^{1 / 2}$, and the normalized particle velocity $\left(V_{p}^{\prime}\right)$ is defined as $V_{p}^{\prime}=V_{p} /\left(2 g^{\prime} H\right)^{1 / 2}$. The velocity variations of the monitoring particles in $\mathrm{T} 1$ and $\mathrm{T} 3$ are plotted in Fig. 3a and 3b, respectively. To highlight the fracture effect along the joint, only the stage when the block reached and traveled on the arc path was plotted $\left(t^{\prime}=1.443 \sim 1.808 \mathrm{~s}\right)$. In general, the velocity curves may continuously fluctuate due to the interaction between the rock block and sliding path, which leads to stress wave propagation and a tiny velocity difference inside the block (Zhao et al., 2017), as shown in Fig. 3. At the very beginning, the velocity of all monitoring particles is the same. When the rock block reached the arc section of the path, the velocities of the monitored particles at different positions began to diverge. The first local fragmentation time $\left(\mathrm{S}_{1 \mathrm{~T} 1}\right)$ corresponds to the time when vigorous fluctuations in the velocities of all monitoring particles appeared, i.e., $t^{\prime}=1.527 \mathrm{~s}$. $\mathrm{S}_{2 \mathrm{~T} 1}$ is the time when the 
velocities of the P3 and P6 particles bifurcated, i.e., $t^{\prime}=1.585 \mathrm{~s}$. Then, the joint fell into the transient fracturing stage (with a duration time of $0.00257 \mathrm{~s}$ ) and completely fractured at $t^{\prime}=1.587 \mathrm{~s}$. After $t^{\prime}=1.617 \mathrm{~s}$, the three monitored particles in the front subblock maintained their velocity differences and continued to move, while the velocities of the three particles in the rear subblock gradually converged. With time passed by, further fragmentation, i.e., $\mathrm{S}_{3 \mathrm{~T} 1}$, occurs at $t^{\prime}=1.750 \mathrm{~s}$, at which the velocities of the monitored particles abruptly fluctuated once again. Fig. $3 \mathrm{~b}$ shows the velocity variations of the monitored particles of T3. As revealed in Fig. 3b, two velocity variations at $t^{\prime}=1.519$ and $1.589 \mathrm{~s}$ of the monitored particles were recorded, which correspond to the $\mathrm{S}_{1 \mathrm{~T} 3}$ and $\mathrm{S}_{2 \mathrm{~T} 3}$ local fragmentation stages. After that, velocity separation of $\mathrm{P}_{3}$ and $\mathrm{P}_{6}$ particles was observed at $t^{\prime}=1.627 \mathrm{~s}$, i.e., the $\mathrm{S}_{3 \mathrm{~T} 3}$ stage, which is similar to $\mathrm{S}_{2 \mathrm{~T} 1}$. The duration time of the fracturing stage in $\mathrm{S}_{3 \mathrm{~T} 3}(0.00154)$ is significantly shorter than that of $\mathrm{T} 1$.

The velocity increases of $\mathrm{P}_{5}$ and $\mathrm{P}_{6}$ at $\mathrm{S}_{3 T 3}$ are larger and more transient than those at $\mathrm{S}_{2 \mathrm{~T} 1}$ at the cracking stage. The velocities of $\mathrm{P} 1$ and $\mathrm{P} 3$ at $\mathrm{S}_{3 \mathrm{~T} 3}$ experience energetic increases and decreases at the very beginning of the cracking stage, which does not occur for $\mathrm{S}_{2 \mathrm{~T} 1}$. As revealed by Fig. 3, the microvelocity variation between the block separating stage $\left(\mathrm{S}_{2 \mathrm{~T} 1}\right)$ and block cracking stage $\left(\mathrm{S}_{3 \mathrm{~T} 3}\right)$ has different characteristics, which may indicate different microkinetics and energy conversion styles between block interaction/collision and the dynamic fragmentation of rock mass (which will be discussed in the following section).

The velocity variations in the monitoring particles show a certain difference between the separating $\left(\mathrm{S}_{2 \mathrm{~T} 1}\right)$ and cracking $\left(\mathrm{S}_{3 \mathrm{~T} 3}\right)$ stages of the block. To quantify the influences of the microscopic differences in the separating and cracking processes on the movement of the block system, the mean horizontal velocities $\left(V_{b}\right)$ of the entire block and rear and front subblocks were calculated. $V_{b}$ is defined as

$V_{b}=\frac{\sum_{i}^{n} v_{x, i} m_{i}}{\sum_{i}^{n} m_{i}}$

where $n$ is the total number of particles in the calculated region and $v_{x, i}$ and $m_{i}$ are the horizontal velocity and mass of particle $i$, respectively. Here, $V_{b}$ is normalized as $V_{b}{ }_{b}=V_{b} /\left(2 g^{\prime} H\right)^{1 / 2}$ for analysis. Fig. 4a plots the normalized mean horizontal velocities $\left(V_{b}^{\prime}\right)$ of $\mathrm{T} 1$ and $\mathrm{T} 3$ versus time. Corresponding to Fig. 2 , the times when different local fragmentation and joint separations of blocks occurred, i.e., $S_{1 \mathrm{~T} 1}, S_{2 \mathrm{~T} 1}, S_{3 \mathrm{~T} 1}, S_{1 \mathrm{~T} 3}, \mathrm{~S}_{2 \mathrm{~T} 3}$ and $\mathrm{S}_{3 \mathrm{~T} 3}$, are also marked in Fig. 4a. From Fig. 4a, it can be reached that the obvious fluctuation times of $V_{b}^{\prime}$ also appear at that marked time, which matches well with the times when the velocities of the monitored particles abruptly change (Fig. 3). At the local fragmentation stages $\left(\mathrm{S}_{1 \mathrm{TT} 1}, \mathrm{~S}_{1 \mathrm{~T} 3}, \mathrm{~S}_{2 \mathrm{~T} 3}\right), V_{b}^{\prime}$ of the front subblock increased rapidly when collision occurred, while $V_{b}^{\prime}$ of the rear subblock first presented a rapid decrease and then recovered in a short time. Additionally, it was observed that $V_{b}^{\prime}$ of the T3 rear subblock recovered to a higher level than before after a rapid decrease at $\mathrm{S}_{1 \mathrm{~T} 3}$ and $\mathrm{S}_{2 \mathrm{~T} 3} . V_{b}^{\prime}$ of the $\mathrm{T} 1$ rear subblock only recovers to the precollision value after a rapid decrease at $\mathrm{S}_{1 \mathrm{~T} 1}$. Meanwhile, $V_{b}{ }_{b}$ of the $\mathrm{T} 3$ entire block increased significantly at the local fragmentation stages (i.e., $S_{1 T 3}$ and $S_{2 T 3}$, while that of $T 1$ only presented a minor increase at its local fragmentation stage $S_{1 T 1}$. This contrast may be due to the local fragmentation at the frontal bottom of the front subblock causing the horizontal ejection of some fragments that gain high velocity from strain energy release (Fig. 2). 
At the separating stage $\left(\mathrm{S}_{2 \mathrm{~T} 1}\right), V_{b}^{\prime}$ of the $\mathrm{T} 1$ front subblock rapidly increases, while $V_{b}^{\prime}$ of the rear subblock inversely decreases. The $V_{b}^{\prime}$ of the $\mathrm{T} 1$ entire block first experienced a slight decrease, and then part of the lost velocity recovered in a short time. Similar to $\mathrm{S}_{2 \mathrm{~T} 1}, V_{b}^{\prime}$ of the $\mathrm{T} 3$ front subblock and rear subblock experienced the same increasing and decreasing phases at the cracking stage $\left(\mathrm{S}_{3 \mathrm{~T} 3}\right)$, respectively. However, the increase in $V_{b}^{\prime}$ of the $\mathrm{T} 3$ front subblock is more energetic than that of the T1 front subblock at this stage. Moreover, as illustrated in Fig. 4a, the $V^{\prime}{ }_{b}$ of the T3 entire block shows a slight increase at $S_{3 T 3}$, which is different from that of the T1 entire block at $S_{2 T 1}$. Particularly, in $S_{3 T 1}, V_{b}^{\prime}$ of the entire block and rear and front subblocks all decrease when the two subblocks collide at the middle top point, and then, $V_{b}^{\prime}$ of the T1 entire block recovers to the value before collision or slightly higher than before. Notably, the $V_{b}^{\prime}$ values of T3 are generally higher than those of $\mathrm{T} 1$ after the blocks slide onto the arc path (1.48 s-1.78 s).

To analyze the energy variations in the fragmentation process, the kinetic energy of the entire block, the rear subblock and the front subblock in both T1 and T3 are calculated. Here, the kinetic energy of the block is calculated as

$E=\sum_{i}^{n} \frac{1}{2} m_{i}\left(v_{x, i}^{2}+v_{y, i}^{2}\right)$

where $n$ is the total number of particles in the calculated region; $v_{x, i}$ and $v_{y, i}$ are the horizontal and vertical velocities of particle $i$, respectively; and $m_{i}$ is the mass of particle $i$. Fig. $4 \mathrm{~b}$ shows the variations in the normalized kinetic energies $\left(E^{\prime}=E / m g^{\prime} H\right)$ of $\mathrm{T} 1$ and $\mathrm{T} 3$ versus travel time. It should be noted that only $E^{\prime} / 2$ of the entire block (half-value of the normalized kinetic energy of the entire block) is plotted in Fig. 4 for better observation.

Similar to the variations in the mean horizontal velocity for the rock block (Fig. 4a), in the local fragmentation stages of T1 and T3 $\left(S_{1 T 1}, S_{1 T 3}, S_{2 \mathrm{~T} 3}\right)$, the kinetic energy of the rear subblock significantly decreases, while that of the front subblock obviously increases. Corresponding to such variation, ejection of small fragments at the frontal bottom part of the block after impact was observed, as shown in Fig. 2. Meanwhile, this local fragmentation caused by impact is accompanied by a sudden decrease in the total kinetic energy of the entire block, which indicates that the impact-fragmentation process consumes energy. However, although $E$ ' of the T3 entire block shows a decreasing trend at the local fragmentation stage, the mean horizontal velocity $\left(V_{b}^{\prime}\right)$ of the T3 entire block presents an increasing trend at this stage, as described above (Fig. 4a). Thus, this increase in the mean velocity of the $\mathrm{T} 3$ entire block may be derived from energy conversion due to greater vertical velocity loss.

At the separating stage, $\mathrm{S}_{2 \mathrm{~T} 1}$, the kinetic energies of the entire block, rear subblock and front subblock all suddenly decrease, while $E^{\prime}$ of the front block rapidly recovers and increases after the sudden decrease. The variation in $E$ ' of T3 shows different characteristics at $\mathrm{S}_{3 \mathrm{~T} 3}$, with $E^{\prime}$ of the $\mathrm{T} 3$ front subblock increasing more than that of T1. More interestingly, $E^{\prime}$ of the entire block for T3 quickly rebounds after a transient slight decrease. The magnitudes of the variations in $E$ ' for the rear and front subblocks of $\mathrm{T} 3$ at $\mathrm{S}_{3 \mathrm{~T} 3}$ are much larger than those at $\mathrm{S}_{2 \mathrm{~T} 1}$.

Moreover, after the separation of subblocks for T1, the rear subblock impacts and pushes the front block at the middle top part $\left(\mathrm{S}_{3 \mathrm{~T} 1}\right)$. At $\mathrm{S}_{3 \mathrm{~T} 1}, E^{\prime}$ of the $\mathrm{T} 1$ entire block and the rear and front subblocks all decrease. After this point, $E^{\prime}$ of the $\mathrm{T} 1$ front subblock gradually recovers, but $E^{\prime}$ of the $\mathrm{T} 1$ entire block and rear subblock continuously decrease. This phenomenon 
illustrates a typical collision-induced momentum transfer process (Heim, 1932; Van Gassen \& Cruden, 1990; Miao et al., 2001).

\subsection{Energy variation}

At the local fragmentation stage $\left(\mathrm{S}_{1 \mathrm{~T} 1}, \mathrm{~S}_{1 \mathrm{~T} 3}, \mathrm{~S}_{2 \mathrm{~T} 3}\right)$, one can clearly see an increasing trend of velocity and kinetic energy for the front part of the block mass and an opposite trend for the rear part of the block mass. More importantly, the variations in the block velocity and the kinetic energy of the entire block are very different between $S_{2 \mathrm{~T} 1}$ and $S_{3 T 3}$. In this section, the effects of joint fracturing and block fragmenting on the redistribution of energy are quantified. For this analysis, the mean horizontal velocity before and after subblock separation in each test ( $v_{b e}$ and $v_{a f}$ ) is calculated; then, the incremental ratio in the separation stage of each test is calculated $\left(\varphi_{v}=\left(v_{a f}-v_{b e}\right) / v_{b e}\right) . \varphi_{v}$ of the entire block, and rear and front subblocks in the tests are all obtained. For the two-joint conditions (T4, T5 and T6) (Fig. 1, insert table), subblocks usually separate along the frontal joint first. Then, separation along the other joint will occur that is accompanied by concomitant impacting, fragmenting, rolling and sliding of fragments, resulting in very complicated monitoring curves. Thus, only the velocity incremental ratio of the front joint separation under such conditions is presented and analyzed here. The same method is used to calculate their block kinetic energy incremental ratios $\left(\varphi_{e}=\left(E_{a f}-E_{b e}\right) / E_{b e}\right.$, where $E_{b e}$ and $E_{a f}$ are the kinetic energies of the rock block before and after joint separation). Fig. 5 is the calculated results of $\varphi_{v}$ and $\varphi_{e}$.

275 From Fig. 5, it can be observed that the $\varphi_{v}$ and $\varphi_{e}$ values of the rear subblock in each test are all less than 0 , indicating that the rear subblock lost its horizontal velocity and kinetic energy in the joint fracturing stage. For the tests with the same joint set, $\varphi_{v}$ and $\varphi_{e}$ of their entire blocks show increasing trends versus joint strength. For $\varphi_{v}$ under different joint sets, both of them increase from nearly 0 to higher values, and the increased rate of the tests with both joint sets is higher than that characterized by one joint set. Different from $\varphi_{v}, \varphi_{e}$ of the entire blocks under both joint set conditions are all negative values, and both display increasing trends versus joint strength with their values tending to 0 , while $\varphi_{v}$ increases to a positive value and $\varphi_{e}$ gradually approaches 0 when the joint has strength. $\varphi_{v}$ of the front subblocks in both joint sets present increasing trends versus increasing joint strength with all values positive. The highest incremental ratio of $\varphi_{v}$ reaches $15 \% . \varphi_{e}$ of the front subblocks also show increasing trends versus joint strength, with the highest incremental percentage exceeding $15 \%$. Different from the regular increasing variations of $\varphi_{v}$ and $\varphi_{e}$ of the entire block and front subblock, those of the rear 285 subblocks present a different feature versus joint strength, which is composed of an increasing part and a following decreasing trend.

According to the curves shown in Fig. 5b, the relationship between the kinetic energy incremental ratio $\left(\varphi_{e}\right)$ of the front subblock and the tensile strength of the joints ( $\sigma$, which represents the general strength of rock mass) can be described by a linear fitting function: 
The linear fitting function (3) shows that the energy of the front subblock is greatly enhanced after joint fracturing (which represents the cracking process or the simplest fragmentation process) as the rock mass strength increases. Note that the linear fitting function (equation 3) is only presented here to describe the increasing trend of $\varphi_{e}$ with rock strength but is not enough to be considered as a real relationship between $\varphi_{e}$ and $\sigma$ because of insufficient data points.

\subsection{Deposit characteristics}

Fig. 6 presents the final deposit features of all simulated conditions. The yellow line represents the distal travel distance of each test. As exhibited in Fig. 6, the travel distance of the simulated conditions with one joint set presents an increasing trend versus joint strength. The higher the joint strength is, the higher the fragmentation degree of the propagated rock mass. Different laws were revealed for the tests with both joint sets designed. For the tests with both joint sets designed (i.e., T4,

300 T5, and T6), their fragmentation degrees are more intensive compared with the tests with one joint designed (i.e., T1, T2, and T3). However, as the joint strength increases, their travel distance presents a decreasing trend. Their fragmentation presents an increasing trend first and then falls into a decreasing trend. Furthermore, the fragmentation degrees of the frontal subblocks are obviously higher than that of the rear subblock for all tests. The deposits of all tests show good preservation of their initial rock mass sequence, which has also been reported in many natural rock avalanches.

\section{Discussion}

\subsection{Elastic strain energy conversion caused by fragmentation}

\subsubsection{Variation in elastic strain energy during fragmentation}

Here, the energy conversion and transformation of the sliding mass during the joint fracturing period are discussed. McSaveney and Davies (2006) indicated that the remaining strain energy stored in fragmented rock pieces after cracking may convert to kinetic energy, which allows fragments to fly outward during dynamic fragmentation in avalanching. Over a long period of time, few direct experiments or numerical simulations illustrate this energy variation related to the fragmenting rock mass movement process (Haug et al., 2016; Zhao et al., 2017). In this study, conversion of the elastic strain energy during rock mass fragmentation and sliding was observed. In the linear parallel bond model, both the linear and bond springs can bear stress and generate elastic strain when acted on by a force, although part of the energy may be consumed by

315 dashpots (Potyondy \& Cundall, 2004). Thus, the strain energies carried by both the linear $\left(E_{s}\right)$ and bond $\left(E_{b s}\right)$ springs were calculated with the total strain energy $\left(E_{t s}=E_{s}+E_{b s}\right)$ being obtained by PFC2D. The elastic strain energy variations of T1 and T3 versus time are shown in Fig. 7a, which are normalized by the maximum total strain energy $\left(E_{t s-m a x}\right)$ for better comparison. As shown in Fig. 7a, $E_{b s}$ is larger than $E_{s}$ most of the time, indicating that the parallel bonds carry more strain energy than linear springs between discs when pressuring. Clearly, it is difficult to distinguish the deformation partitioning between minerals (discs) and substrates (bonds) in a rock block. Thus, this energy distribution between linear springs and parallel 
bonds is controlled by the contact model that we selected and the microparameters that we used and cannot be compared with that of real rock. The variation in these two strain energy components is synchronized. Compared with Fig. 3 and Fig. 4, one can find that the time of the peak values of the total strain energy is consistent with the time when abrupt fluctuations of the particle velocity, block velocity and kinetic energy occurred. In addition, the value of the elastic strain energy in the cracking stage of $\mathrm{T} 3\left(\mathrm{~S}_{3 \mathrm{~T} 3}\right)$ is greatly larger than that in the cracking stage of $\mathrm{T} 1\left(\mathrm{~S}_{2 \mathrm{~T} 1}\right)$, indicating that the rock block accumulated more strain energy before fracture.

Fig. $7 \mathrm{~b}$ shows the variation in energy dissipation during the rock mass movements of T1 and T3. Energy dissipation is composed of energy dissipated by frictional slip $\left(E_{\mu}\right.$, slip energy) and energy dissipated by dashpots $\left(E_{\beta}\right.$, dashpot energy represents the energy loss by the collision of discs). The total dissipated energy $\left(E_{t d}=E_{\mu}+E_{\beta}\right)$ was also calculated. The dissipated energy is simply normalized by the maximum value of the total energy value $\left(E_{t d-m a x}\right)$ during the joint fracturing stage. Fig. $7 \mathrm{~b}$ also shows the variation of the bond breakage numbers of $\mathrm{T} 1$ and $\mathrm{T} 3$ versus time, which were normalized by the total number of broken bonds. As exhibited in Fig. 7b, the development of the bond breakage number and the trend of dissipated energy are synchronized, which is also consistent with the variations of the strain energy shown in Fig. 7a. In general, the dashpot energy is larger than the slip energy. Both of them increase with time. The total energy dissipation of T1 is always larger than that of T3. Additionally, the bond breakage number of T1 is greater than that of T3 at the very beginning of movement, which is attributed to the initial debonded joint of T1. Combined with the variations in the kinetic energy shown in Fig. 4, the energy conversion of the sliding mass in cracking time $\left(\mathrm{S}_{3 \mathrm{~T} 3}\right)$ can be deduced. First, when the rock block slides along the arc path and interacts with the path surface, part of the kinetic energy is transformed into elastic strain energy stored in bonds and linear springs. Second, once the impact force is greater than the bond strength in local positions, the bond breaks, and the elastic strain energy stored in the broken bond vanishes. As the number of broken bonds increases, a crack forms. During this period, the bond breakage number increases. Third, as the crack continues to develop and the block rebounds, the impact force gradually decreases. At the same time, the remainder of the strain energy stored in the entire block is released, which eventually converts to the kinetic energy of fragments. As indicated by Fig. 7, the cracking process along the joint $\left(S_{3 T 3}\right.$, the simplest fragmentation) does not consume much energy, while the energy consumption of the local fragmentation $\left(\mathrm{S}_{1 \mathrm{~T} 1}, \mathrm{~S}_{3 \mathrm{~T} 1}, \mathrm{~S}_{1 \mathrm{TT} 3}\right.$ and $\left.\mathrm{S}_{3 \mathrm{~T} 3}\right)$ and the separation of the no-strength joint $\left(\mathrm{S}_{2 \mathrm{~T} 1}\right)$ consume more energy.

\subsubsection{Energy transfer caused by fragmentation}

As described above, in T1, we set a joint without tensile strength. With this design, the motion and separation process of two closely packed blocks was simulated and reproduced. During the separation stage (i.e., from $S_{2 T 1}$ to $S_{3 T 1}$ ), the front subblock of T1 gains horizontal velocity ( $\uparrow 3.72 \%)$, with the rear subblock losing part of its horizontal velocity ( $\downarrow 5.30 \%)$, as shown in Fig. 4a. Meanwhile, the kinetic energy of the front subblock increases after a sharp decrease during separation $(\uparrow 4.47 \%)$, while that of the rear subblock shows a continuous decrease $(\downarrow 4.17 \%)$, as illustrated in Fig. 4 b. This is a typical momentum transfer phenomenon caused by continued collisions between the rear and front subblocks, which is very common in 
granular flows (Heim, 1932; Manzella \& Labiouse, 2009; Lai et al., 2017). Considering that the tensile strength of the joint in $\mathrm{T} 1$ is 0 , collisions are the interaction form between the front and rear subblocks during the joint fracturing process. Hence, we describe this phenomenon as collision-induced energy transfer.

Different from T1, a joint with tensile strength is designed in T3 with the fracturing process of a rock block along a weak joint being simulated. As revealed in Fig. 4, the front subblock of T3 also presents an increase in the horizontal velocity $(\uparrow 12.56 \%)$ and kinetic energy $(\uparrow 15.23 \%)$, with the rear subblock displaying a decrease $(\downarrow 8.89 \%, \downarrow 6.30 \%)$. Considering that the tensile strength of the joint in $\mathrm{T} 3$ is not 0 , we describe this phenomenon $\left(\mathrm{S}_{3 \mathrm{~T} 3}\right)$ as fragmentation-induced energy transfer. According to Figs. 4, 5 and 7, the fragmentation-induced energy transfer from the rear subblock to the front subblock in T3 is due to the release of elastic strain energy and its conversion to kinetic energy, which is also inferred in the literature (Zhang et al., 2000; Li et al., 2005; Davies \& McSaveney, 2009; De Blasio \& Crosta, 2015). Through a comparison of the kinetic energy evolutions of the entire blocks in T1 and T3 (Fig. 4b), it is reached that fragmentation-induced energy transfer can clearly lead to a greater kinetic energy $\left(E^{\prime}\right)$ increase in the frontal subblock and less energy lost in the entire blocks ( $\downarrow 0.07 \%$ ) than collision-induced energy transfer (with $10.76 \%$ energy lost of entire block) (Fig. 7b). Since the efficiency of fragmentation-induced energy transfer is higher than that of collision-induced energy transfer and fragmentation is also a pervasive phenomenon in natural rock avalanches, we suggest that dynamic fragmentation may play a more efficient runoutenhanced role in the spreading of rock masses than particle interactions within unbreakable granular flow during the emplacement processes of rock avalanches. Field investigations show that many rock avalanches with high degrees of fragmentation have unpredicted thin deposits (Crosta et al., 2017; Wang et al., 2018b, 2018c), which may be related to fragmentation-induced energy transfer, as indicated by the results.

However, as shown in Fig. 6, the travel distance of the fragmenting rock block shows an increasing trend with joint strength for one joint set situation, while there are no clues that relate the deposit characteristics to the joint strength and energy boosting of frontal rock fragments for two joint situations. In our opinion, the travel distance of the sliding mass with both joint sets in the DEM simulation is a more complex process, which is controlled by the interaction of the fragment system and the contact model used in the simulation. As stated by Lin et al. (2020a), although the linear parallel bond model used in DEM can successfully simulate the fracture process of sliding mass and interaction of granular flow, it is unable to accurately replicate the energy dissipation of complex fragmenting flow. Zhao et al. $(2017,2018)$ also reported such results in their similar DEM simulation. In their simulation results, the relationship between the degree of fragmentation and travel distance of fragmenting rock mass movements is inverse with the relationship of the previous experimental results (Bowman et al., 2012; Haug et al., 2016). Thus, the fragmentation effects may fade away with the increasing complexity of the fragmenting rock mass movement system (from one joint system to two joint systems) in DEM simulations.

\subsection{Cross-scale effects caused by rock fragmentation}

385 With the design of joints characterized by different strengths and numbers, a simplified fragmentation process of rock masses was simulated in this study, which provides insights into the contribution of fragmentation in rock mass propagation. 
Although the simplified study cannot reproduce the real fragmentation process of natural rock avalanches, some of the results can still provide insights into rock avalanche propagation. Therefore, a primary discussion on the cross-scale effects caused by rock fragmentation based on the simulated results and natural rock avalanches is conducted in the following, hoping to provide insights into the fragmenting emplacement process of natural cases.

With this study, the elastic strain energy release caused by fragmentation is primarily indicated. Energy conveying between the front and rear subblocks caused by the fragmentation process was reached, which promoted the forward movement of the front subblock and hindered the movement of the rear subblock (Fig. 4 and Fig. 5). Such energy conversion and transfer effects caused by fragmentation have also been discussed in previous studies (Zhang et al., 2000; Lin et al., 2020b; Haug et al., 2016; Bowman et al., 2012). As shown in Fig. 8a and 8b, rock blocks at the surface of a sliding rock mass (carapace facies) may experience this kind of dynamic fragmentation (thus, fragments after block fragmentation carry much kinetic energy).

Generally, normal stress- and shear stress-induced fragmentation processes are concentrated under the carapace facies in natural rock avalanches (Estep \& Dufek, 2013; De Blasio \& Crosta, 2015; Zhang \& McSaveney, 2017). For dense granular flow (e.g., rock avalanches), force chains commonly occur. Grains in the force chain experience a higher stress than surrounding grains (Fig. 8c); thus, they break first when the stress in the force chain is equal to the failure strength of a grain. The entire conversion and transfer process of one rock block observed in our simulation may also reproduce as one episode of rock dynamic fragmentation in this force chain for real rock avalanches (Fig. 8c). Note that for a force chain, the strain rate, confining pressure and fracture form do not change the nature of energy conversion during the fragmentation of the rock block (Ghaffari et al., 2019). However, the occurrence of confined pressure in a force chain may alter the elastic strain energy releasing mode. Based on our simulation results, the broken fragments spread out with some kinetic energy when there is no confined pressure, as mentioned above (Fig. 8b) (Zhang et al., 2000; Davies \& McSaveney, 2009), causing the transformation of part of the elastic strain energy to the kinetic energy of fragments (energy transfer effects caused by fragmentation). However, since the grains in the force chains of natural rock avalanches are closely packed under high confined pressure, there is not enough space for the elastic strain energy stored inside the broken grains to be released in the form of the kinetic energy of fragments. For this reason, the strain energy is released in the form of outward elastic stress pressure, which is also called an elastic body wave by Davies et al. (2019b) (in Fig. 8d). Thus, the energy transfer effects caused by rock dynamic fragmentation indicated by our simulations will still occur by means of outward elastic body waves in a natural rock avalanche, which eventually affects the movement of the avalanche. Based on the physics of elastic stress wave propagation, there are three effects caused by elastic stress waves released from rock fragmentation for an entire rock avalanche:

(1) Sliding preferentially occurs in the local dynamic fragmentation region of a grain in a force chain. As shown in Figs. 2 and 3, fragmented fragments separate because the elastic strain energy is released outward. In a natural rock avalanche, these outward elastic stress waves introduced by rock dynamic fragmentation can eventually cause the release of pressure carried by other force chain grains and the surroundings (stress drop after dynamic fragmentation, Fig. 8e). Then, sliding may occur 
as the shear stress remains unaltered and the normal stress carried by force chains suddenly decreases (de Arcangelis et al., 2018).

(2) The propagation of elastic stress rarefaction waves superimposed on the stress field of the sliding mass causes the local normal stress to decrease and allows sliding to occur at locations where fragmentation does not occur (Fig. 8e) (Melosh, 1979; Johnson et al., 2016; Davies and McSaveney, 2016).

(3) The elastic stress wave superimposed on the stress field of the sliding mass boosts the local normal stress and allows the next fragmentation to occur at another location.

Note that all three of these effects are based on elastic stress wave fluctuations caused by fragmentation. For the entire basal layer or main body in rock avalanches, each fragmentation event may cause one elastic stress wave release according to our simulation results. Rarefaction stress wave-induced local sliding (Johnson et al., 2016) can occur within the entire sliding mass and become more concentrated near the bottom of the sliding mass (Fig. 8e). Rarefaction stress-induced local sliding is controlled by stress wave propagation and interaction, rock strength in the force chain, overburden pressure, local shear rate and so on. Therefore, the shear layer in the rock avalanche may become thicker due to the random occurrence of local sliding. Moreover, the concentration of rarefaction stress-induced local sliding in the body facies may lead to the formation of local shear bands despite the low shear rate in the main sliding mass. In contrast, rock breaks when the local superimposed stress exceeds the grain strength in the body facies (Fig. 8e); then, a jigsaw structure forms, and the main part of the strain energy is released as an elastic stress wave once again (Davies \& McSaveney, 2009). The jigsaw structure may remain in the deposit due to the tightly packed rock mass during the propagation of the rock avalanche and the persistence of grain fragmentation until the rock avalanche stops.

\section{Conclusions}

The fracturing and fragmentation processes of a sliding rock block and their influences on energy transformation in the system are investigated using DEM simulations. We find that fragmentation can greatly affect the kinetic variations in different parts of the rock mass. When the joint in the middle of a rock block cracks, the front subblock gains additional kinetic energy, while the rear subblock loses part of its kinetic energy, leading to a long travel distance for the distal part (in the one-joint situation). These kinetic energy variations are due to elastic strain energy release during fracturing, which is similar to the momentum transfer process caused by collisions in a multiblock system. However, our results show that energy transfer induced by fragmentation is more efficient than that induced by collision.

The influence of rock strength on the energy transmission in the fragmented mass is also explored. The results show that the kinetic energy increase in the front subblock becomes larger with increasing strength. This variation in kinetic energy indicates that a rock mass with higher strength experiences more energetic fragmentation effects. However, no strong relationship is found between the strain energy incremental ratio and travel distance, indicating that the fragmentation effects may fade away with the increasing complexity of the fragmenting rock mass movement system. 
We qualitatively examine the effects of rock dynamic fragmentation on the propagation of rock avalanches and the formation of some deposit structures. The elastic strain energy transmission process caused by fragmentation in our numerical simulations can be described as elastic body wave release based on Davies and McSaveney (2019). Then, three possible effects caused by elastic stress waves released from rock fragmentation for an entire rock avalanche are addressed.

\section{Data availability}

The datasets supporting this research are stored open access on Zenodo (https://doi.org/10.5281/zenodo.3729541).

\section{Author contributions}

460 All authors contributed to the data analysis, discussion and improvement of the test, which has been written mostly by QL and YW. Each author contributed to different parts, here listed: Conceptualisation: QL, QC and YW, Funding acquisition: QC and YW, Numerical simulations: YX and KD; Writing: QL and YW.

\section{Competing interests}

The authors declare that they have no conflict of interest.

\section{Acknowledgements}

We are grateful to Fengshou Zhang, Yuanyuan Zhou, Xiaolong Lin, Zhanqiang Ren and Shitao Liu for their assistance with the DEM simulation and data processing. This research was supported by the National Natural Science Foundation of China (41941017, 41877226, and 41877237) and the Second Tibetan Plateau Scientific Expedition and Research (STEP) program (grant no. 2019QZKK0906). We would like to thank American Journal Experts (www.aje.com) for English language editing.

\section{References}

Bi, W., Delannay, R., Richard, P., Taberlet, N., and Valance, A.: Two- and three-dimensional confined granular chute flows: Experimental and numerical results. J Phys-Condens Mat, 17(24), 2457-2480. https://doi.org/10.1088/09538984/17/24/006, 2005.

Bowman, E.T., Take, W.A., Rait, K.L., and Hann, C.: Physical models of rock avalanche spreading behaviour with dynamic 475 fragmentation. Can Geotech J, 49(4), 460-476. https://doi.org/10.1139/t2012-007, 2012.

Collins, G.S., and Melosh, H.J.: Acoustic fluidization and the extraordinary mobility of sturzstroms. J Geophys Res, 108(B10), 2473. https://doi.org/10.1029/2003JB002465, 2003. 
Crosta, G.B., Franttini, P., and Fusi, N.: Fragmentation in the Val Pola rock avalanche, Italian Alps. J Geophys Res, 112(F1), 290-303. https://doi.org/10.1029/2005jf000455, 2007.

Crosta, G.B., Hermanns, R.L., Dehls, J., Lari, S., and Sepulveda, S.: Rock avalanches clusters along the northern Chile coastal scarp. Geomorphology, 289, 27-43. https://doi.org/10.1016/j.geomorph.2016.11.024, 2017.

Crosta, G.B., Frattini, P., Valbuzzi, E., and De Blasio, F.V.: Introducing a new inventory of large Martian landslides. Earth Space Sci, 5(4), 89-119. https://doi.org/10.1002/2017EA000324, 2018.

Cruden, D.M., and Hungr, O.: The debris of the Frank slide and theories of rockslide-avalanche mobility. Can J Earth Sci, 23(3): 425-432. https://doi.org/ 10.1139/e86-044, 1986.

Cundall, P.A.: A computer model for simulating progressive large scale movements in blocky rock systems. In: Proc. Symp. Int. Soc. Rock Mech, Nancy, France, 129-136, 1971.

Cundall, P.A., and Strack, O.D.L.: A discrete numerical model for granular assemblies. Géotechnique 29(1):47-65. https://doi.org/10.1680/geot.1980.30.3.331, 1979.

Davies, T.R., and McSaveney, M.J.: A fragmentation spreading model for long-runout avalanches. Can Geotech J, 36(6), 1096-1110. https://doi.org/10.1139/t99-067, 1999.

Davies, T.R., and McSaveney, M.J.: The role of rock fragmentation in the motion of large landslides. Eng Geol, 109(1-2), 67-79. https://doi.org/10.1016/j.enggeo.2008.11.004, 2009.

Davies, T.R.H., and Mcsaveney, M.J.: Comment on "The Reduction of Friction in Long-Runout Landslides as an Emergent

Phenomenon" by Brandon C. Johnson, Charles S. Campbell, and H. Jay Melosh. J Geophy Res-Earth, https://doi.org/10.1002/2016JF003954, 2016.

Davies, T.R., Reznichenko, N.V., and McSaveney, M.J.: Energy budget for a rock avalanche: fate of fracture-surface energy. Landslides, https://doi.org/10.1007/s10346-019-01224-5, 2019a.

Davies, T.R., McSaveney, M.J., and Reznichenko, N.V.: What happens to Fracture Energy in Brittle Fracture? Revisiting the Griffith Assumption. Solid Earth Discussions, https://doi.org/10.5194/se-2019-59, 2019b.

De Arcangelis, L., Lippiello, E., Ciamarra, M., and Sarracino, A.: Induced and endogenous acoustic oscillations in granular faults. Phil. Trans. R. Soc. A 377, 20170389. http://dx.doi.org/10.1098/rsta.2017.0389, 2018.

De Blasio, F.V., and Crosta, G.B.: Fragmentation and boosting of rock falls and rock avalanches. Geophy Res Lett, 42(20), 8463-8470. https://doi.org/10.1002/2015GL064723, 2015.

505 De Blasio, F.V., Dattola, G., and Crosta, G.B.: Extremely Energetic Rockfalls. J Geophy Res-Earth, 123(10), $2392-2421$. https://doi.org/10.1029/2017JF004327, 2018.

Dufresne, A., Bösmeier, A., and Prager, C.: Sedimentology of rock avalanche deposits - Case study and review. Earth-Sci Rev, 163, 234-259. https://doi.org/10.1016/j.earscirev.2016.10.002, 2016.

Estep, J., and Dufek, J.: Discrete element simulations of bed force anomalies due to force chains in dense granular flows. J

Volcanol Geoth Res, 254, 108-117. https://doi.org/10.1016/j.jvolgeores.2012.12.023, 2013. 
Evans, S.G., Guthrie, R.H., and Roberts, N.J.: The disastrous 17 February 2006 rockslide-debris avalanche on Leyte Island, Philippines: a catastrophic landslide in tropical. Nat Hazard Earth Sys, 7, 89-101. https://doi.org/10.5194/nhess-7-89-2007, 2007.

Fan, X.M., Xu, Q., Scaringi, G., Dai, L., Li, W., and Dong, X.: Failure mechanism and kinematics of the deadly June 24th 2017 Xinmo landslide, Maoxian, Sichuan, China. Landslides, 14(6), 2129-2146. https://doi.org/10.1007/s10346-0170907-7, 2017.

Foda, M.A.: Landslides riding on basal pressure waves. Continuum Mech Therm, 6(1), 61-79. https://doi.org/10.1007/bf01138307, 1994.

Ghaffari, H.O., Griffith, W.A., and Barber, T.J.: Energy delocalization during dynamic rock fragmentation. Geophys J Int, 217, 1034-1-46. https://doi.org/10.1093/gji/ggz064, 2019.

Giani, G., Migliazza, M., and Segalini, A.: Experimental and theoretical studies to improve rock fall analysis and protection work design. Rock Mech Rock Eng, 37(5), 369-389. https://doi.org/10.1007/s00603-004-0027-2, 2004.

Goguel, J.: Scale-dependent rockslide mechanisms, with emphasis on the role of pore fluid vaporization. Rockslides and Avalanches, 14(1), 693-705. https://doi.org/10.1016/B978-0-444-41507-3.50028-3, 1987.

Grady, M.E., and Kipp, D.E.: Dynamic rock fragmentation// In Atkinson B K (ed) Fracture mechanics of rock. Academic Press, 429-475. https://doi.org/10.1016/B978-0-12-066266-1.50006-5, 1987.

Habib, P.: Production of gaseous pore pressure during rock slides. Rock Mech Rock Eng, 7(4), 193-197. https://doi.org/10.1007/BF01246865, 1975.

Haug, O.T., Rosenau, M., Leever, K., and Oncken, O.: On the Energy Budgets of Fragmenting Rockfalls and Rockslides: Insights from Experiments. J Geophy Res-Earth, 121(7), 1310-1327. https://doi.org/10.1002/2014JF003406, 2016.

Heim, A.: Landslides and human lives. Vancouver, Bitech Publishers, 1932.

Hsü, K.J.: Catastrophic Debris Streams generated by Rockfalls. Geol Soc Am Bull, 86(1), 129-140. https://doi.org/10.1130/0016-7606(1975)862.0.CO;2, 1975.

Hu, W., Huang, R., and Mcsaveney, M.: Mineral changes quantify frictional heating during a large low-friction landslide. Geology, 46(3). https://doi.org/ 10.1130/G39662.1, 2018.

Hungr, O., and Evans, S.G.: Entrainment of debris in rock avalanches: An analysis of a long run-out mechanism. Geol Soc Am Bull, 116(9), 1240-1252. https://doi.org/10.1130/B25362.1, 2004.

Imre, B., Laue, J., and Springman, S.M.: Fractal fragmentation of rocks within sturzstroms: insight derived from physical experiments within the ETH geotechnical drum centrifuge. Granul Matter, 12(3), 267-285. https://doi.org/10.1007/s10035-009-0163-1, 2010.

Johnson, B.C., Campbell, C.S., and Melosh, H.J.: The reduction of friction in long runout landslides as an emergent phenomenon. J Geophy Res-Earth, 121(5), 881-889. https://doi.org/ 10.1002/2015JF003751, 2016.

Kent, P.E.: The transport mechanism in catastrophic rock falls. J Geol, 74(1), 79-83. https://doi.org/ 10.2307/30075179, 1966. 
545 Kermani, E., Qiu, T., and Li, T.: Simulation of collapse of granular columns using the discrete element method. Int J Geomech 15(6), 04015004. https://doi.org/10.1061/(asce)gm.1943-5622.0000467, 2015.

Lai, Z.Q., Vallejo, L.E., Zhou, W., Ma, G., Espitia, J.M., and Caicedo, B.: Collapse of granular columns with fractal particle size distribution: Implications for understanding the role of small particles in granular flows. Geophy Res Lett, 44(24), 12181-12189. https://doi.org/ 10.1002/2017GL075689, 2017.

550 Langlois, V.J., Quiquerez, A., Allemand, P.: Collapse of a two-dimensional brittle granular column: Implications for understanding dynamic rock fragmentation in a landslide. J Geophy Res-Earth, 120(9), 1866-1880. https://doi.org/10.1002/2014jf003330, 2015.

Legros, F.: The mobility of long runout landslides. Eng Geol, 63(3-4), 301-331. http://doi.org/10.1016/S00137952(01)00090-4, 2012.

555 Li, X.B., Lok, T.S., and Zhao, J.: Dynamic characteristics of granite subjected to intermediate loading rate. Rock Mech Rock Eng, 38(1), 21-39. https://doi.org/10.1007/s00603-004-0030-7, 2005.

Li, W.C., Li, H.J., and Dai, F.C.: Discrete element modeling of a rainfall-induced flowslide. Eng Geol y, 149-150(2), 22-34. https://doi.org/10.1016/j.enggeo.2012.08.006, 2012.

Lin, Q.W., Cheng, Q.G., Xie, Y., Zhang, F.S., Li, K., Wang, Y.F., and Zhou, Y.Y.: Simulation of the fragmentation and propagation of jointed rock masses in rockslides: DEM modeling and physical experimental verification. Landslides. https://doi.org/10.1007/s10346-020-01542-z, 2020a.

Lin, Q.W., Cheng, Q.G., Li, K., Xie, Y., and Wang, Y.F.: Contributions of rock mass structure to the emplacement of fragmenting rockfalls and rockslides: insights from laboratory experiments. J Geophy Res-Sol Ea, 125(4). https://doi.org/10.1029/2019jb019296, 2020b.

565 Lo, C.M., Lin, M.L., Tang, C.L., and Hu, J.C.: A kinematic model of the Hsiaolin landslide calibrated to the morphology of the landslide deposit. Eng Geol, 123, 22-39. https://doi.org/10.1016/j.enggeo.2011.07.002, 2011.

Lo, C.M., Lee, C.F., Chou, H.T., and Lin, M.L.: Landslide at su-hua highway 115.9k triggered by typhoon megi in taiwan. Landslides, 11(2), 293-304. https://doi.org/ 10.1007/s10346-013-0435-z, 2014.

Locat, P., Couture, R., Leroueil, S., Locat, J., and Jaboyedoff, M.: Fragmentation energy in rock avalanches. Can Geotech J, 43(8), 830-851. https://doi.org/10.1139/t06-045, 2006.

Lucas, A., Mangeney, A., and Ampuero, J.P.: Frictional velocity-weakening in landslides on Earth and on other planetary bodies. Nat Commun, 5, 3417. https://doi.org/10.1038/ncomms447, 2014.

Ma, G., Zhang, Y., and Zhou W.: The effect of different fracture mechanisms on impact fragmentation of brittle heterogeneous solid. Int J Impact Eng, 113, 132-143. https://doi.org/10.1016/j.ijimpeng.2017.11.016, 2018.

575 Manzella, I., and Labiouse, V.: Flow experiments with gravel and blocks at small scale to investigate parameters and mechanisms involved in rock avalanches. Eng Geol, 109(1-2), 146-158. https://doi.org/ 10.1016/j.enggeo.2008.11.006, 2009. 
McSaveney, M.J., and Davies, T.R.H.: Rapid rock mass flow with dynamic fragmentation: inferences from the morphology and internal structure of rockslides and rock avalanches//Evans S G, et al. (eds.), Landslides from Massive Rock Slope Failure, Netherlands, 285-304. https://doi.org/10.1007/978-1-4020-4037-5_16, 2006.

Melosh, H.J.: Acoustic fluidization: A new geology process? J Geophys Res, 84(B13), 7513-7520. https://doi.org/10.1029/JB084iB13p07513, 1979.

Miao, T.D., Liu, Z.Y., Niu, Y.D., and Ma, C.W.: A sliding block model for the runout prediction of high-speed landslides. Can Geotech J, 38(2), 217-226. https://doi.org/10.1139/cgj-38-2-217, 2001.

Morgan, J., and McGovern, P.: Discrete element simulations of gravitational volcanic deformation: 1. Deformation structures and geometries. J Geophys Res, 110, B05402. https://doi.org/10.1029/2004JB003252, 2005.

Murugaratnam, K., Utili, S., and Petrinic, N.: A combined DEM-FEM numerical method for Shot Peening parameter optimization. Adv Eng Softw 79:13-26. https://doi.org/10.1016/j.advengsoft.2014.09.001, 2015.

Perinotto, H., Schneider, J.L., Bachelery, P., Le Bourdonnec, F.X., Famin, V., and Michon, L.: The extreme mobility of debris avalanches: A new model of transport mechanism. J Geophy Res-Sol Ea, 120(12), 8110-8119. https://doi.org/10.1002/2015JB011994, 2015.

Pollet, N., and Schneider, J.L.M.: Dynamic disintegration processes accompanying transport of the Holocene Flims sturzstrom (Swiss Alps). Earth Planet Sc Lett, 221(1-4), 433-448. https://doi.org/10.1016/s0012-821x(04)00071-8, 2004.

Potyondy, D.O., and Cundall, P.A.: A bonded-particle model for rock. Int J Rock Mech Min, 41(8), 1329-1364. doi:10.1016/j.ijrmms.2004.09.011, 2004.

Preuth, T., Bartelt, P., Korup, O., and McArdell, B.W.: A random kinetic energy model for rock avalanches: Eight case studies. J Geophy Res-Earth, 115(F3), F03036. https://doi.org/10.1029/2009jf001640, 2010.

Pudasaini, S.P., and Hutter, K.: Avalanche dynamics: dynamics of rapid flows of dense granular avalanches. Springer Berlin, New York. https://doi.org/10.1007/978-3-540-32687-8, 2007.

600 Rait, K.L., Bowman, E.T., and Lambert, C.: Dynamic fragmentation of rock clasts under normal compression in sturzstrom. Geotech Lett, 2(3), 167-172. http://dx.doi.org/10.1680/geolett.12.00038, 2012.

Sassa, K.: Geotechnical model for the motion of landslides. Paper presented at the 5th International Symposium on Landslides, Rotterdam: A A Balkema., 1988.

Scheidegger, A.E.: On the Prediction of the Reach and Velocity of Catastrophic Landslides. Rock Mech Rock Eng, 5(4), 231-236. https://doi.org/10.1007/BF01301796, 1973.

Shen, W., Zhao, T., and Crosta, G.: Analysis of impact-induced rock fragmentation using a discrete element approach. Int J Rock Mech Min, 98, 33-38. https://doi.org/10.1016/j.ijrmms.2017.07.014, 2017.

Shreve, R.L.: The Blackhawk landslide. Geological Society of America Special Paperhttps://doi.org/10.1130/SPE108-p1, 1968.

610 Silbert, L., Ertas, D., Grest, G., and Halsey, T.: Granular flow down an inclined plane: Bagnold scaling and rheology. Phys Rev E, 64, 051302. https://doi.org/ 10.1103/PhysRevE.64.051302, 2001. 
Strom, A.L.: Morphology and internal structure of rockslides and rock avalanches; grounds and constraints for their modelling. In: Evans, S.G., Scarascia-Mugnozza, G., Strom, A.L., Hermanns, R.L. (Eds.), Landslides from Massive Rock Slope Failure. NATO Science Series: IV, Earth and Environmental Sciences. Springer, Dordrecht, 305-326. https://doi.org/10.1007/978-1-4020-4037-5_17, 2006.

Thompson, N., Bennett, M.R., and Petford, N.: Development of characteristic volcanic debris avalanche deposit structures: New insight from distinct element simulations. J Volcanol Geoth Res, 192(3-4), 191-200. https://doi.org/10.1016/j.jvolgeores.2010.02.021, 2010.

Timar, G., Kun, F., Carmona, H. A., and Herrmann, H. J.: Scaling laws for impact fragmentation of spherical solids. Phys Rev E, 86(1), 016113. https://doi.org/ 10.1103/PhysRevE.86.016113, 2012.

Van Gassen, W., and Cruden, D.M.: Momentum transfer and friction in the debris of rock avalanches. Can Geotech J, 26(4), 623-628. https://doi.org/10.1139/t89-075, 1989.

Wang, F.W., Sassa, K., and Wang, G. H.: Mechanism of a long-runout landslide triggered by the August 1998 heavy rainfall in Fukushima Prefecture, Japan. Eng Geol, 63:169-185. https://doi.org/10.1016/s0013-7952(01)00080-1, 2002.

Wang, Y.F., Cheng, Q.G., and Zhu, Q.: Surface microscopic examination of quartz grains from rock avalanche basal facies. Can Geotech J, 52(2), 167-181. https://doi.org/ 10.1139/cgj-2013-0284, 2015.

Wang, Y.F., Dong, J.J., and Cheng, Q.G.: Velocity-dependent frictional weakening of large rock avalanche basal facies: Implications for rock avalanche hypermobility? J Geophy Res-Sol Ea, 122(3), 1648-1676. https://doi.org/10.1002/2016JB013624, 2015.

Wang, Y.F., Dong, J.J., and Cheng, Q.G.: Normal Stress-Dependent Frictional Weakening of Large Rock Avalanche Basal Facies: Implications for the Rock Avalanche Volume Effect. J Geophy Res-Sol Ea, 123(4), 3270-3282. https://doi.org/10.1002/2018JB015602, 2018a.

Wang, Y.F., Cheng, Q.G., Shi, A.W., Yuan, Y.Q., Yin, B.M., and Qiu, Y.H.: Sedimentary deformation structures in the Nyixoi Chongco rock avalanche: Implications on rock avalanche transport mechanisms. Landslides, 16(3), 523-532. https://doi.org/10.1007/s10346-018-1117-7, 2018b.

Wang, Y.F., Cheng, Q.G., Lin, Q.W., Li, K., and, Yang, H.F. Insights into the kinematics and dynamics of the Luanshibao rock avalanche (Tibetan Plateau, China) based on its complex surface landforms. Geomorphology, 317, 170-183. https://doi.org/10.1016/ j.geomorph.2018.05.025, 2018c.

Wang, Y., Tonon, F.: Dynamic validation of a discrete element code in modeling rock fragmentation.

Int J Rock Mech Min, 48(4), 535-545. http://dx.doi.org/10.1016/j.ijrmms.2011.02.003, 2011.

Weidinger, J.T., Korup, O., Munack, H., Altenberger, U., Dunning, S.A., and Tippelt, G.: Giant rockslides from the inside. Earth Planet Sc Lett, 389, 62-73. https://doi.org/10.1016/j.eps1.2013.12.017, 2014.

Yoon, J.: Application of experimental design and optimization to PFC model calibration in uniaxial compression simulation. Int J Rock Mech Min, 44(6), 871-889. https://doi.org/10.1016/j.ijrmms.2007.01.004, 2007. 
Zhang, Z.X., Kou, S.Q., Jiang, L.G., and Lindqvist, P.A. Effects of loading rate on rock fracture. Int J Rock Mech Min, 37(5), 745-762. https://doi.org/10.1016/S1365-1609(00)00008-3, 2000.

Zhang, M., and Mcsaveney, M.J.: Rock-avalanche deposits store quantitative evidence on internal shear during runout. Geophy Res Lett, 44(17), 8814-8821. https://doi.org/ 10.1002/2017GL073774, 2017.

Zhao, T., Crosta, G.B., Utili, S., and De Blasio, F.V. Investigation of rock fragmentation during rockfalls and rock avalanches via 3-D discrete element analyses. J Geophy Res-Sol Ea, 122, 678-695. https://doi.org/10.1002/2016JF004060, 2017.

Zhao, T., Crosta, G.B., Dattola, G., and Utili, S.: Dynamic fragmentation of jointed rock blocks during rockslide-avalanches: Insights from discrete element analyses. J Geophy Res-Sol Ea, 123(4), 3250-3269. https://doi.org/ 10.1002/2017JB015210, 2018.

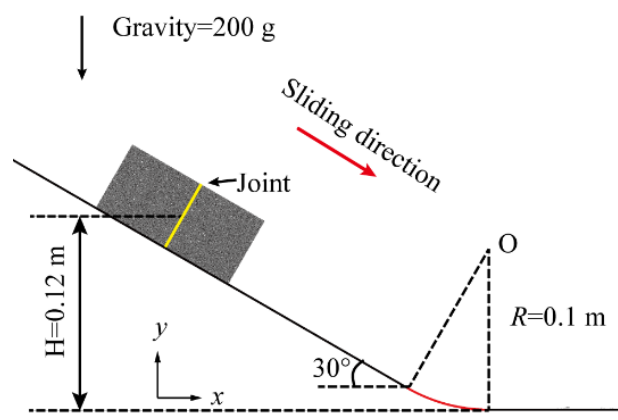

\begin{tabular}{|c|c|c|c|}
\hline \multirow{2}{*}{ Configuration } & \multicolumn{3}{|c|}{ Tensile strength of joints (MPa) } \\
\cline { 2 - 4 } & 0 & 4.39 & 8.61 \\
\hline & $\mathrm{T} 1$ & $\mathrm{~T} 2$ & $\mathrm{~T} 3$ \\
\hline & $\mathrm{T} 4$ & $\mathrm{~T} 5$ & $\mathrm{~T} 6$ \\
\hline
\end{tabular}

Figure 1: Schematic view of the model configuration. The detailed configurations of jointed rock blocks are shown in the inset table, and yellow lines in gray blocks represent the positions of joints. The joints with a width of $3 \mathrm{~mm}$ and a length of 45 mm equally divide the block.

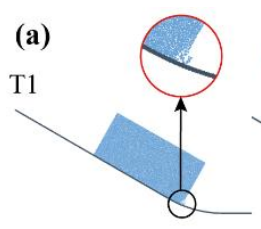

$\mathrm{S}_{1 \mathrm{~T} 1}$

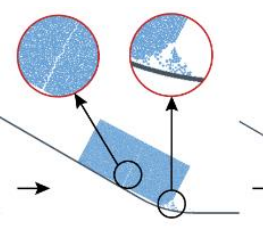

$\mathrm{S}_{2 \mathrm{~T} 1}$

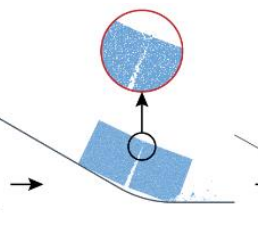

$\mathrm{S}_{3 \mathrm{~T} 1}$
Final deposition

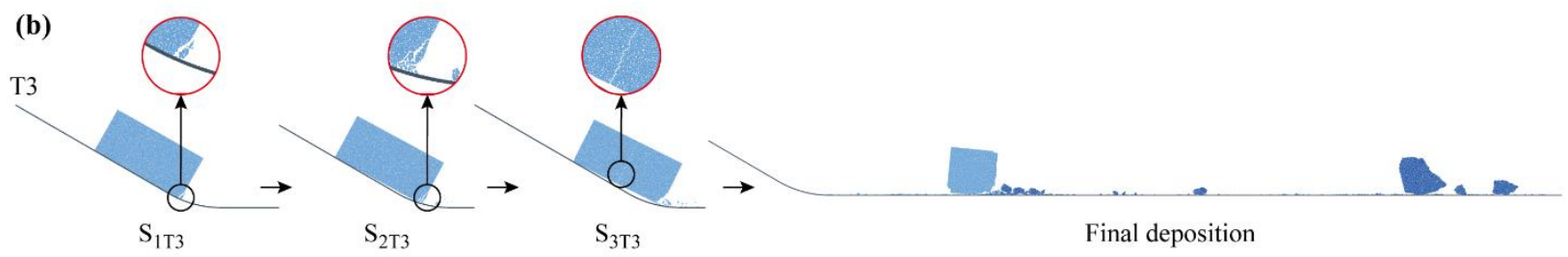

Figure 2: (a) The evolution of T1 in the initial stage of fragmentation and its depositional characteristics. (b) The evolution of T3 in the initial stage of fragmentation and its depositional characteristics $\left(S_{1 T 1}, S_{2 T 1}, S_{3 T 1}, S_{1 T 3}\right.$, $S_{2 T 3}$ and $S_{3 T 3}$ represent three specific 
https://doi.org/10.5194/nhess-2021-127

Preprint. Discussion started: 7 May 2021

(c) Author(s) 2021. CC BY 4.0 License.

stages/times for T1 and T3 that are described and analyzed later). The light blue subblock in the final deposition stage represents the rear part of the entire block, and the dark blue subblock represents the front part of the entire block.

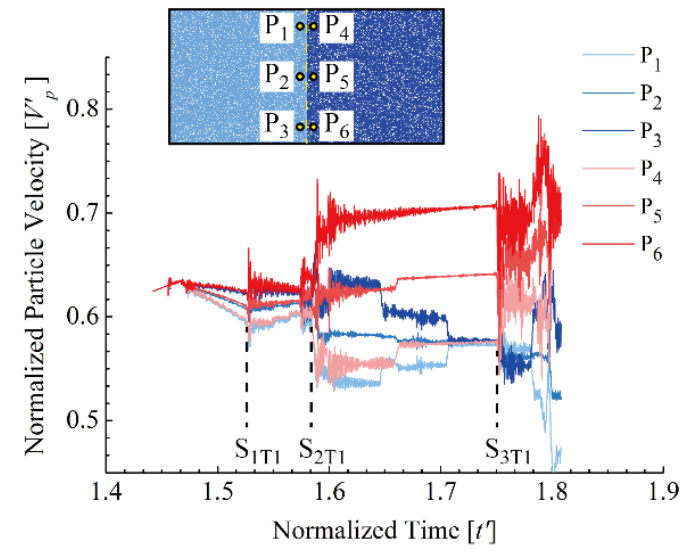

(a) $\mathrm{T} 1$

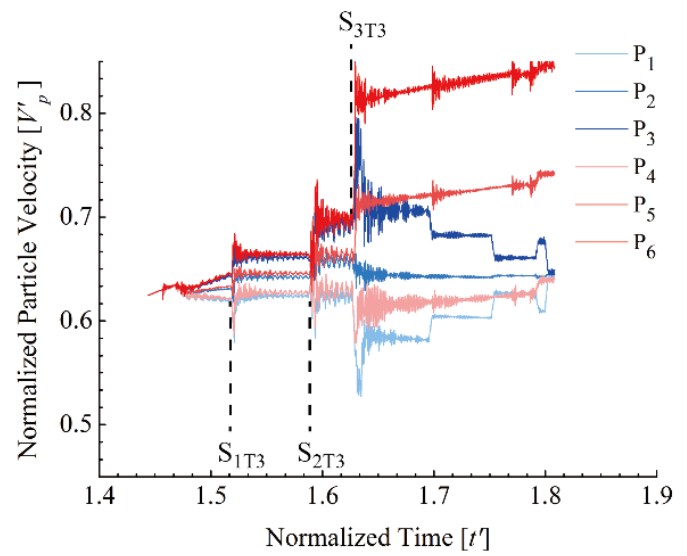

(b) $\mathrm{T} 3$

Figure 3: (a) Normalized particle velocities of monitoring particles in $\mathrm{T} 1$ versus time (inset picture shows the relative positions of the six monitoring particles; $\left.t^{\prime}=t /\left(2 \mathrm{H} / \mathrm{g}^{\prime}\right)^{1 / 2} ; V_{p}^{\prime}=V /\left(2 \mathrm{~g}^{\prime} \mathrm{H}\right)^{1 / 2}\right)$. (b) Normalized particle velocities of monitoring particles in $\mathrm{T} 3$ versus time.

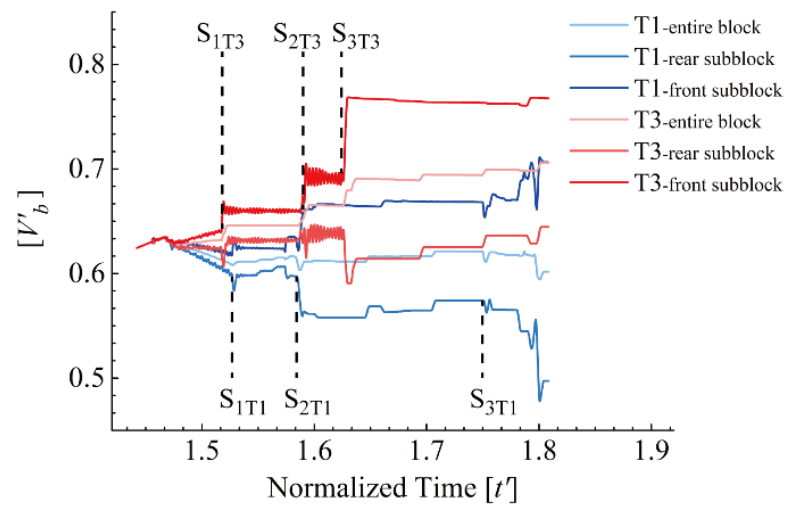

(a)

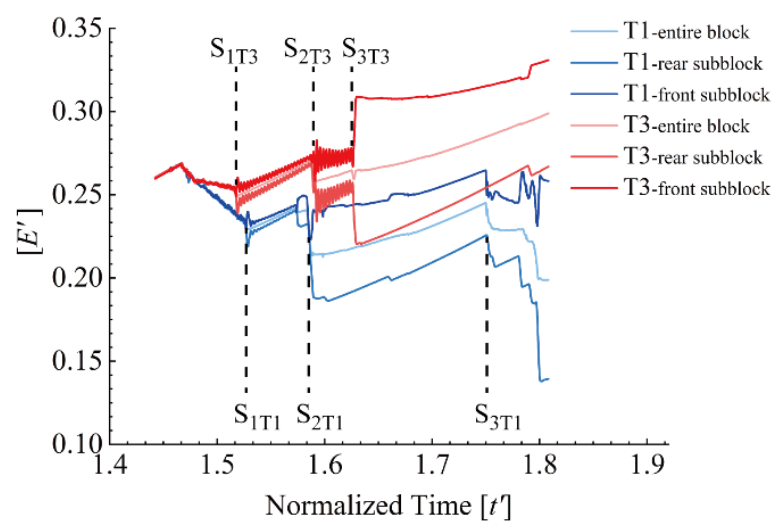

(b)

Figure 4: (a) The normalized horizontal velocities of blocks in $\mathrm{T} 1$ and $\mathrm{T} 3$ versus time $\left(V^{\prime}{ }_{b}=V_{b} /\left(2 g^{\prime} H\right)^{1 / 2}\right)$. (b) The normalized kinetic energy evolution of blocks in $\mathrm{T} 1$ and $\mathrm{T} 3$ versus time $\left(E^{\prime}=E / m g ' H\right)$. Note that $\mathrm{E}^{\prime} / 2$ of the entire block is plotted. 
https://doi.org/10.5194/nhess-2021-127

Preprint. Discussion started: 7 May 2021

(c) Author(s) 2021. CC BY 4.0 License.

(c) (i)

(a)

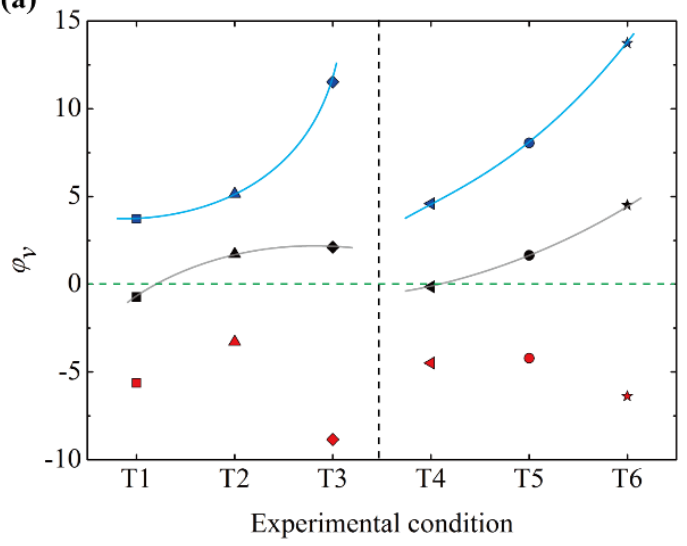

(b)

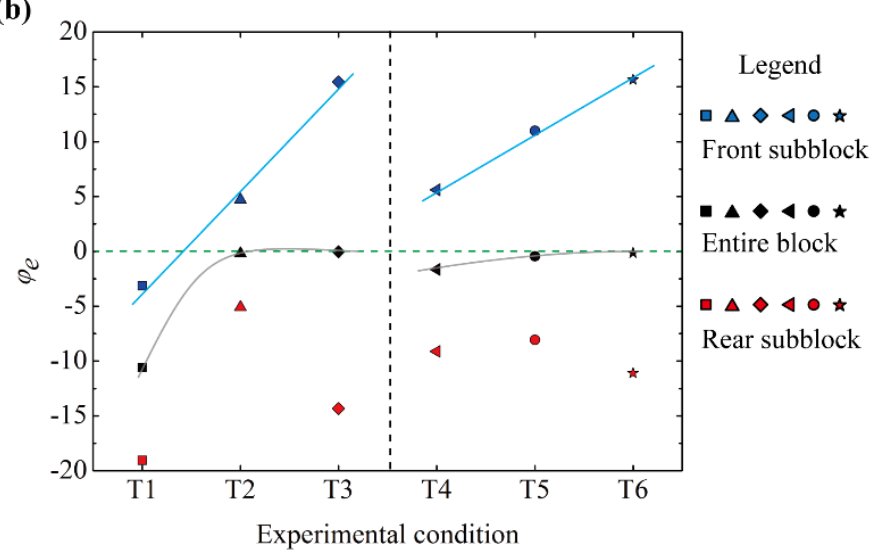

Figure 5: (a) The mean horizontal velocity incremental percentage $\left(\varphi_{v}\right)$ and (b) the kinetic energy incremental percentage $\left(\varphi_{e}\right)$ in the block separation stage for all tests.

$\mathrm{T} 1$

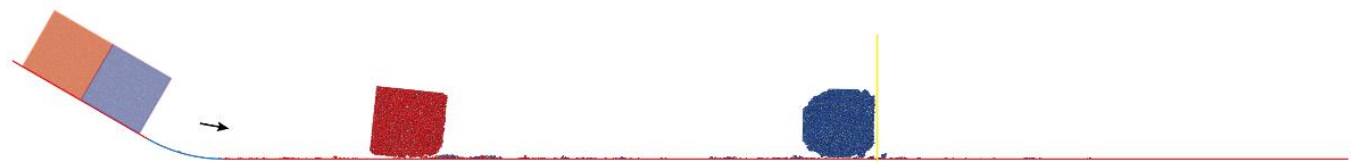

$\mathrm{T} 2$

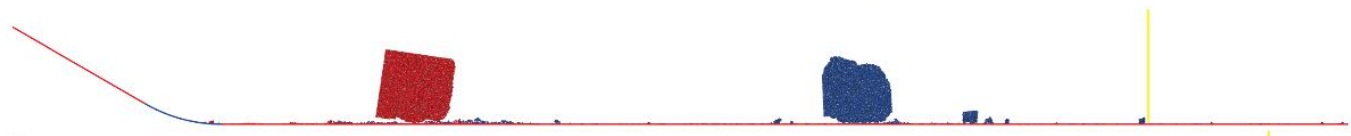

$\mathrm{T} 3$

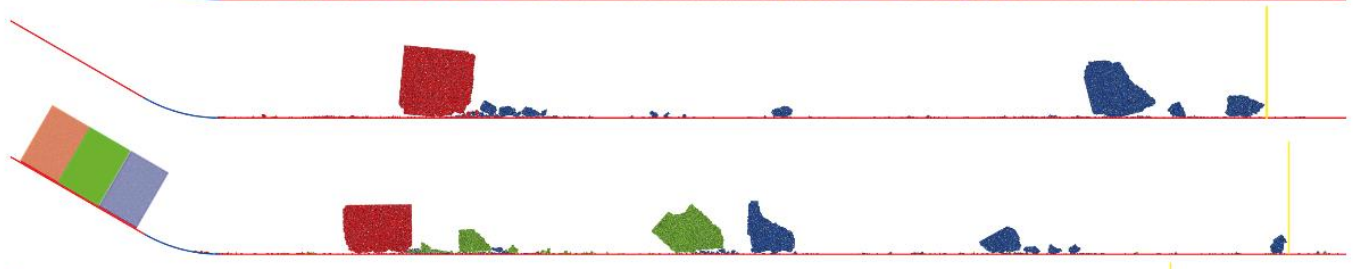

T5

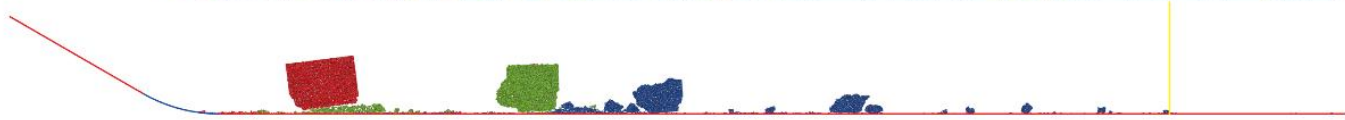

T6

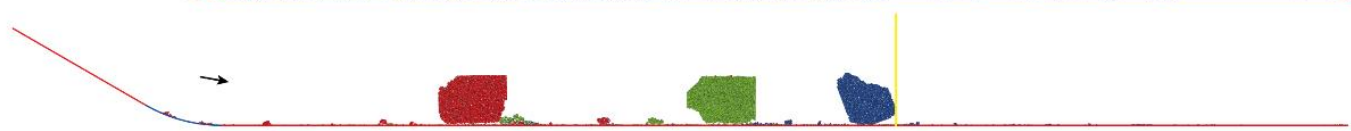

Figure 6: Deposit profiles of all simulations. Yellow line represents travel distance of rock mass. 
https://doi.org/10.5194/nhess-2021-127

Preprint. Discussion started: 7 May 2021

(c) Author(s) 2021. CC BY 4.0 License.
Natural Hazards

and Earth System

Sciences

Discussions

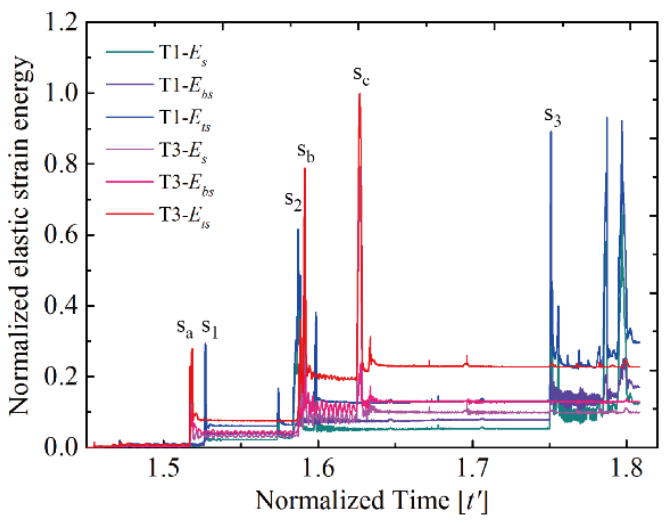

(a)

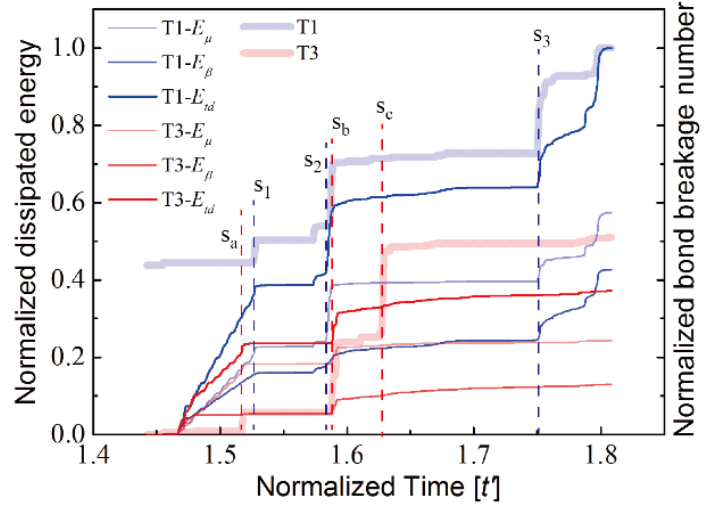

(b)

Figure 7: (a) The normalized elastic strain energy variation in the sliding block in T1 and T3 (normalized by the maximum total strain energy, $E_{t s-m a x}$ ) versus time. (b) Normalized dissipated energy variation in the sliding block in T1 and T3 (normalized by the maximum total dissipated energy, $E_{t d-m a x}$ ) versus time. The two bold curves represent bond breakage number variations (which are also normalized by the maximum bond breakage number) of $\mathrm{T} 1$ and $\mathrm{T} 3$ versus time.

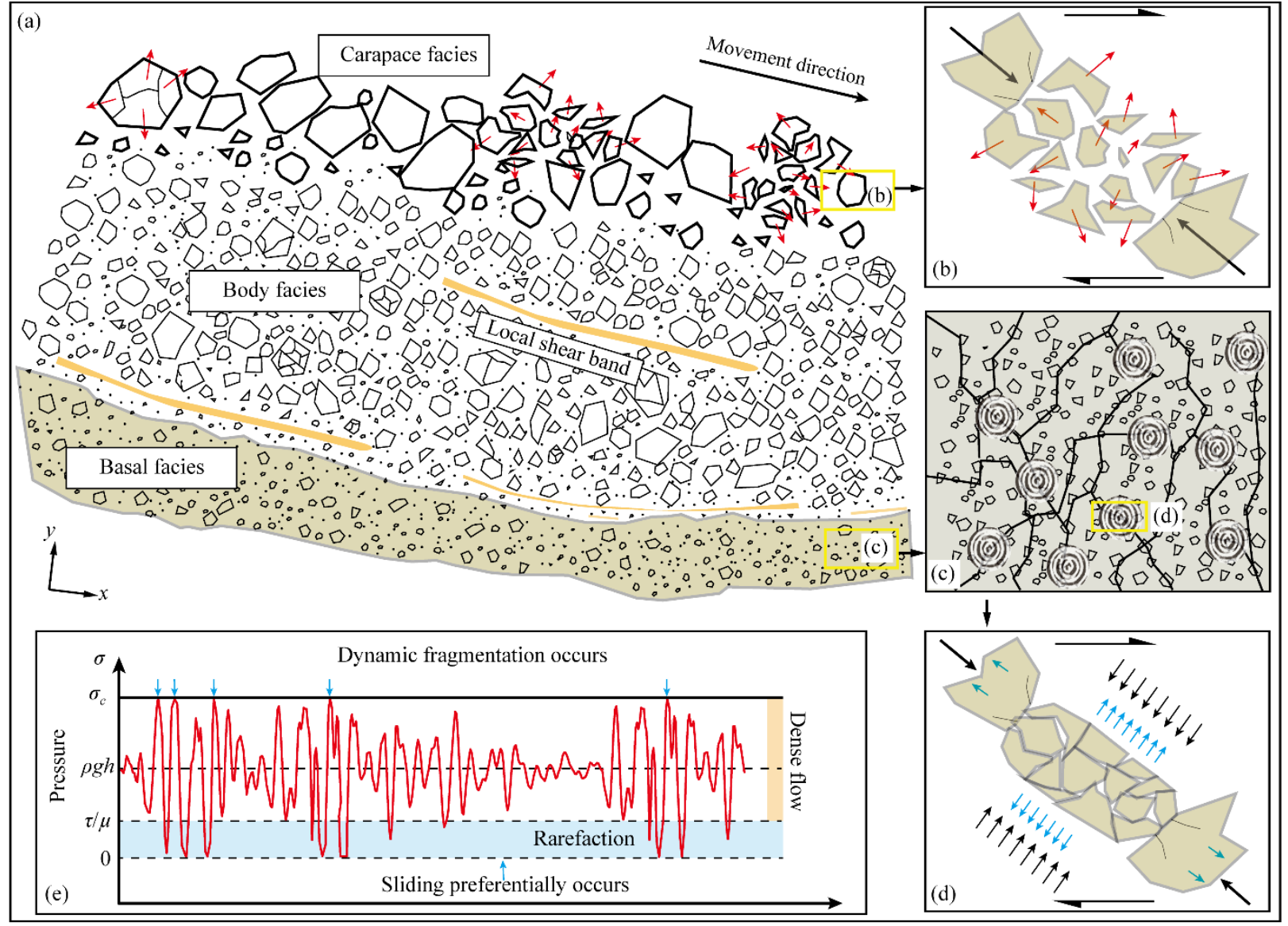


Figure 8: (a) Schematic illustration of fragmentation effects of countless grains during the propagation of a rock avalanche; (b) dynamic fragmentation of a rock block without confining pressure (in the carapace facies); (c) force chain in the shear layer (basal facies) and local fragmentation points (gray-white rings represent the fragmentation points and related radiated stress wave)s; (d) schematic illustration of dynamic fragmentation of a rock block in a force chain with confining pressure (small black arrows represent confining pressure, and small blue arrows represent outward stress caused by fragmentation, which then develop to a stress wave propagating through the entire sliding rock mass) (modified from Melosh (1979)); (e) pressure variation (red curve) of a point inside a rock mass caused by rock fragmentation during an avalanche (modified from Melosh (1979)). Blue arrows represent the times at which dynamic fragmentation occurs. $\sigma_{c}$ is the critical stress for the rock to fracture.

Table 1: Input microparameters of the DEM model.

\begin{tabular}{|c|c|c|c|}
\hline Microparameters & Value & Microparameters & Value \\
\hline Particle radius (mm) & {$[0.1,0.5]$} & Cohesion (MPa) & 95 \\
\hline Number of particles & 11812 & Bond friction angle & $30^{\circ}$ \\
\hline Density $\left(\mathrm{kg} / \mathrm{m}^{3}\right)$ & 2650 & Ball friction coefficient & 0.577 \\
\hline Normal to shear stiffness ratio & 3 & Friction coefficient between ball and wall & 0.577 \\
\hline Bond normal to shear stiffness ratio & 3 & Normal viscous damping & 0.36 \\
\hline Effective modulus (GPa) & 60 & Shear viscous damping & 0.11 \\
\hline Bond effective modulus (GPa) & 40 & Local damping & 0.06 \\
\hline Tensile strength (MPa) & 95 & & \\
\hline
\end{tabular}

\section{Appendix A}

Table A1: List of variables considered in this study.

\begin{tabular}{|c|c|c|c|}
\hline Variable & Description & Variable & Description \\
\hline$H$ & Drop height of a sliding rock block & $v_{b e}$ & Horizontal velocity of block before separation \\
\hline$g$ & Gravitational acceleration on Earth $\left(9.81 \mathrm{~m} / \mathrm{s}^{2}\right)$ & $v_{a f}$ & Horizontal velocity of block after separation \\
\hline g' & $\begin{array}{l}\text { Gravitational acceleration in our DEM model } \\
(200 \mathrm{~g})\end{array}$ & $\varphi_{e}$ & $\begin{array}{l}\text { Kinetic energy incremental ratio of block in } \\
\text { separation stage }\end{array}$ \\
\hline$\sigma$ & Tensile strength of joint & $E_{b e}$ & Kinetic energy of block before separation \\
\hline$t$ & Physical time of simulation & $E_{a f}$ & Kinetic energy of block after separation \\
\hline$t^{\prime}$ & Normalized time scale & $\varphi^{\prime}{ }_{e}$ & $\begin{array}{l}\text { Kinetic energy incremental ratio of front } \\
\text { subblock in } \mathrm{T} 1, \mathrm{~T} 2 \text {, and } \mathrm{T} 3\end{array}$ \\
\hline$V_{p}^{\prime}$ & Normalized particle velocity in simulation & $\varphi{ }^{\prime \prime}{ }_{e}$ & $\begin{array}{l}\text { Kinetic energy incremental ratio of front } \\
\text { subblock in } \mathrm{T} 3, \mathrm{~T} 4 \text {, and } \mathrm{T} 5\end{array}$ \\
\hline$V_{b}$ & Mean horizontal velocity of block & $E_{b s}$ & $\begin{array}{l}\text { Bond strain energy, stored in the parallel bond } \\
\text { springs }\end{array}$ \\
\hline$V_{b}^{\prime}$ & Normalized mean horizontal velocity of block & $E_{\beta}$ & $\begin{array}{l}\text { Dashpot energy, the energy dissipated by the } \\
\text { dashpots }\end{array}$ \\
\hline$E$ & Kinetic energy of rock block & $E_{t d}$ & Total dissipated energy \\
\hline$E^{\prime}$ & Normalized kinetic energy of rock block & $E_{t d-\max }$ & Maximum dissipated energy \\
\hline$i$ & Particle ID & $E_{s}$ & Strain energy of discs, stored in the linear springs \\
\hline$m_{i}$ & Mass of particle $i$ & $E_{\mu}$ & $\begin{array}{l}\text { Slip energy, the energy dissipated by frictional } \\
\text { slip }\end{array}$ \\
\hline$n$ & Total number of particles in rock block & $E_{t s}$ & Total strain energy stored in rock block \\
\hline$v_{x, i}$ & Horizontal velocity of particle $i$ & $E_{t s-\max }$ & Maximum total strain energy \\
\hline$v_{y, i}$ & Vertical velocity of particle $i$ & $\varphi_{v}$ & $\begin{array}{l}\text { Incremental ratio of block velocity in separation } \\
\text { stage }\end{array}$ \\
\hline
\end{tabular}

